\title{
POLÍTICAS PÚBLICAS EDUCATIVAS EN EL CONTEXTO DE AMÉRICA LATINA. UNA PERSPECTIVA DE LA EDUCACIÓN RURAL/ EDUCACIÓN DEL CAMPO EN VENEZUELA Y BRASIL
}

PAULINA ELENA VILLASMIL SOCORRO'

ORCID: https://orcid.org/0000-0002-7298-741X

SAMUEL HILCÍAS CARVAJAL RUÍZ" ORCID: https://orcid.org/0000-0003-0747-296X

ARLETE RAMOS DOS SANTOS "II ORCID: https://orcid.org//0000-0003-0217-3805

CLAUDIO PINTO NUNES "II ORCID: https://orcid.org/0000-0003-1514-6961

I Universidad Nacional Experimental Rafael María Baralt, Maracaibo, Zulia, Venezuela. II Universidad Nacional Experimental Simón Rodríguez, Caracas - Capital, Venezuela. III Universidade Estadual do Sudoeste da Bahia, Vitória da Conquista, Bahia, Brasil.

Paulina Elena V. Socorro - Doutora em Ciências para el Desarrollo Estratégico pela Universidad Bolivariana de Venezuela (UBV). Professora da Universidad Nacional Experimental Rafael María Baralt (UNERMB). E-mail:<paulinavillasmil@gmail.com>.

Samuel H. C. Ruíz - Doutor em Ciências da Educação pela Universitat Autònoma de Barcelona (UAB). Professor da Universidad Nacional Experimental Simón Rodríguez (UNESR). E-mail:< shcarvajal@gmail.com>.

Arlete R. dos Santos - Doutora em Educação pela Universidade Federal de Minas Gerais (UFMG). PósDoutora em Educação pela Universidade Estadual Paulista (UNESP). Professora da Universidade Estadual do Sudoeste da Bahia (UESB). Líder do Grupo de Estudos Movimentos Sociais, Diversidade e Educação do Campo (GEPEMDEC/CNPq). E-mail:< arlerp@hotmail.com>.

Claudio P. Nunes - Doutor em Educação pela Universidade Federal do Rio Grande do Norte (UFRN). PósDoutor em Educação pela Universidade Federal de Minas Gerais (UFMG). Professor da Universidade Estadual do Sudoeste da Bahia (UESB). Líder do Grupo de Estudos Didática, Formação e Trabalho Docente (Difort/ CNPq). E-mail: < claudionunesba@hotmail.com>. 
RESUMEN: Este artículo analiza la evolución y aplicación de las políticas públicas neoliberales implementadas en la América Latina, con impactos en los sistemas educativos públicos y en el ejercicio del derecho de las personas a la educación. El texto se centra en el desarrollo de políticas en los sectores rurales, con foco en la Educación en el Campo, específicamente en Brasil y Venezuela. Es una investigación cualitativa cuyos datos fueron obtenidos a través de revisión bibliográfica y análisis documental. Tomamos como base los análisis de la legislación en los países citados. Los resultados demostraron que en Venezuela hasta el final del siglo XX el acento de las políticas públicas estuvo afinado en la urbanización del rural, con una educación subordinada a la cultura del petróleo. En el caso de Brasil, la educación para los pueblos del campo, protagonizada por los sujetos campesinos, logró numerosas conquistas desde el punto de vista de las políticas educativas. Sin embargo, carece de enfrentamientos constantes entre la clase obrera y la clase dominante.

Palabras-clave:Educación del Campo. Educación Rural. Políticas Educacionales. Políticas Públicas.

\section{POLÍTICAS PÚBLICASEDUCATIVAS NO CONTEXTODA AMÉRICA LATINA: UMA PERSPECTIVA DA EDUCAÇÃO RURAL/EDUCAÇÃO DO CAMPO NA VENEZUELA E NO BRASIL}

RESUMO: Este artigo analisa a evolução e aplicação das políticas públicas neoliberais implementadas na América Latina, com impactos nos sistemas educacionais públicos e no exercício do direito das pessoas à educação. O texto focaliza o desenvolvimento de políticas nos setores rurais, com foco na Educação no Campo, especificamente no Brasil e na Venezuela. É uma pesquisa qualitativa cujos dados foram obtidos através de revisão bibliográfica e análise documental. Tomamos como base as análises da legislação nos países citados. Os resultados demonstraram que na Venezuela até o final do século XX o acento das políticas públicas esteve afinado na urbanização do rural, com uma educação subordinada à cultura do petróleo. No caso do Brasil, a educação para os povos do campo, protagonizada pelos sujeitos campesinos, alcançou numerosas conquistas do ponto de vista das políticas educacionais. Entretanto, carece de enfrentamentos constantes entre a classe trabalhadora e a classe dominante.

Palavras-chave: Educação do campo. Educação Rural. Políticas Educacionais. Políticas Públicas.

\section{EDUCATIONAL PUBLIC POLICIES IN THE CONTEXT OF LATIN AMERICA. A PERSPECTIVE OF RURAL EDUCATION/THE COUNTRYSIDE EDUCATION IN VENEZUELA AND BRAZIL}

ABSTRACT: This article analyzes the evolution and application of neoliberal public policies implemented in Latin America, with impacts on public education systems and in the exercise of people's right to education. The text focuses on the development of policies in the rural sectors, with 
focus on Education in the Field, specifically in Brazil and Venezuela. It is a qualitative research whose data were obtained through bibliographic review and documentary analysis. We took as basis the analysis of the legislation in the mentioned countries. The results showed that in Venezuela, until the end of the twentieth century, the focus of the public policies was concentrated on the urbanization of the rural, with an education subordinated to the petroleum culture. In the case of Brazil, the education for rural people, led by peasant subjects, has achieved many achievements from the point of view of educational policies. However, it lacks constant confrontation between the working class and the dominant class.

Keywords: Field Education. Rural Education. Educational Policies. Public Policies.

\section{POLÍTICAS PÚBLICAS EDUCATIVAS EN EL CONTEXTO DE AMÉRICA LATINA}

A casi cinco décadas de la implantación de la doctrina neoliberal en Nuestramérica, el saldo resulta poco alentador si revisamos someramente los efectos e impactos de este modelo en nuestras sociedades. El Golpe de Estado contra el presidente Salvador Allende marca un punto de inflexión en la historia de la región e inaugura un periodo de violencia política, de persecuciones por razones ideológicas, como mecanismos necesarios de coacción colectiva y de terror, instrumentos fundamentales para el despliegue e implantación del neoliberalismo en los países del Cono Sur americano y por extensión en el resto del continente.

Puello, F. (2015) sostiene que la emergencia del neoliberalismo es un fenómeno en la economía política global que está asociado a dos hitos históricos fundamentales; el primero, “(...) En 1947 con la fundación de la Sociedad de Mont - Pèlerin, cónclave intelectual y plataforma ideológica desde la cual se difunde el pensamiento y las doctrinas neoliberales." (Puello. 2015, p.p: 21) El segundo referente es 1973, año que conjuga el shock petrolero mundial, y de manera determinante, el 11 de septiembre, cuando se materializa el Golpe de Estado contra Salvador Allende, primer presidente socialista elegido a través del voto.

Con este trágico hito histórico se implementa el funesto Plan Cóndor ideado por el Departamento de Estado de los EE. UU., dirigido a instaurar férreas dictaduras en el Cono Sur obedientes a sus designios con un impacto en el resto del continente. Este hecho abre una nueva época por la vía de facto para la imposición de la estrategia regional del capital corporativista, dirigida a la instalación de las "(...) bases del régimen económico - politico neoliberal." (Ibidem, p.p: 22)

El aspecto medular doctrinario del régimen político económico que se inaugura, consistió en la modificación abrupta de 
la acción pública, emprendida entonces por los Estados nacionales, como parte de la función de gobernar, orientada bajo la tesis del estado de bienestar, ${ }^{1}$ a través de políticas restrictivas, de ajustes o reformas de corte neoliberal, regidas por los designios del libre mercado y caracterizadas por su selectividad, por ende, profundamente excluyentes (KLEIN, 2012).

El discurso del reformismo neoliberal arropado por el supuesto argumento de la inoperatividad del Estado, impone así la univocidad de un marco doctrinal del dogma neoclásico que concibe al Estado como el principal obstáculo para la libertad; entendida esta como un eufemismo para modificar la legalidad existente y alinearla a los intereses privativos del capital, por tanto opresivos y excluyentes de las grandes mayorías sociales.

Se instala entonces la doctrina del Estado minimo, tesis desarrollada por el académico austriaco Friedrich August von Hayek, ${ }^{3}$ defensor a ultranza de la autorregulación del mercado y la mínima o ninguna intervención del Estado como condiciones para garantizar un funcionamiento eficiente de la economía, por tanto de las instituciones y la sociedad.

Este giro supone en la práctica una rápida y sostenida privatización de lo público, otrora, texto y contexto del accionar de las instituciones públicas, incentivada ahora por la notable y sistemática campaña de satanización de la figura del Estado, de sus acciones, y la consecuente apropiación de lo público por corporaciones y empresas de diversas funciones. El continuo transcurso privatizador ocurre bajo la excusa de garantizar las libertades económicas, como ya se señaló, y la exigencia de hacer más eficiente y rentable la vieja estructura del Estado y el funcionamiento de la economía en general, sin tutelaje estatal.

En este panorama se anclan ideas fuerza de corte economicista, rápidamente difundidas por el aparataje mediático - cultural que asocia la atención de áreas prioritarias de la sociedad, como son la educación y la salud, por ejemplo, con la noción de gasto público. Por tanto, se legitiman y operan otras lógicas discursivas y prácticas en las acciones de gobierno que transforman el fondo y las formas de las políticas públicas, solapando en algunos casos la intervención privada y el drenaje de dineros públicos hacia manos particulares; en otros casos, mediante la abierta cesión de la competencia pública a capitales privados, sean estos nacionales, extranjeros o mixtos.

Respectoaldogma del "Estado mínimo" esgrimido recurrentemente por el neoliberalismo como coartada para justificar la eficiencia y el protagonismo de la "sociedad civil" en el ámbito de las políticas públicas, Peroni, V. (2013) nos aporta luces al respecto cuando afirma que: 
“(...) el Estado fue históricamente llamado a intentar controlar y regular las contradicciones del capital y la relación capital - trabajo. Actualmente, a pesar del anunciado Estado mínimo, ahora es llamado a 'socorrer' al capital productivo y financiero en los momentos de mayor crisis... el Estado era (es) mínimo para las políticas sociales y máximo para el capital.” (p. 11 -12)

Una fase ulterior de la ofensiva del capitalismo en la región, comprendida entre las décadas de los años 1980 y 1990, es la protagonizada por el llamado Consenso de Washington, bajo la tutoría de la triada Fondo Monetario Internacional (FMI) - Banco Mundial (BM) - Banco Interamericano de Desarrollo (BID), las cuales, siguiendo la doctrina hegemónica, vienen a significar la consolidación del proyecto político y económico del neoliberalismo global en América Latina. Con ello se manifiestan dos fenómenos, a saber, por una parte, la acentuación de la reducción del espacio de las políticas públicas y, por la otra, "(...) el agravamiento de la situación social, el aumento de la desigualdad y la exclusión." (Ibidem, p.p: 22).

La cooptación de las políticas públicas favorables a los intereses del capital en América Latina tuvo expresiones desoladoras en ámbitos tan sensibles como el de la educación. Y no podía ser de otro modo. La propia doctrina del dogma otorga las razones. En primer término, el neoliberalismo trastoca el sentido de la educación como derecho humano fundamental y la cosifica transformándola en un bien de consumo, por tanto, transable como mercancía que al ser concebida como inversión, debe y tiene que ser rentable. Lo anterior viene asociado a la consideración del diagnóstico neoliberal sobre la educación pública, según el cual, se propaga la falacia del fracaso del sistema público. En este sentido, Adriana Puiggrós (1996) afirma:

$[\ldots]$ Los grandes sistemas escolares son ineficientes, inequitativos y sus productos de baja calidad. De tal afirmación se deduce que la educación pública ha fracasado y se justifican políticas de reducción de la responsabilidad del Estado en la educación, presentadas como la única reforma posible. (p. 90)

Sobre estas bases se configuró el modelo de las políticas públicas en educación implementadas por el neoliberalismo en América Latina. La expresión concreta de esta lógica programática fue la profunda desinversión en los sistemas escolares, contribuyendo con el deterioro de la educación pública, de los centros educativos, expulsando a millones de niños y jóvenes de la escuela y configurando así un panorama de exclusión e inequidad social generalizado en la región.

La reacción al modelo neoliberal y sus impactos en las sociedades latinoamericanas tuvo diferentes manifestaciones y consecuencias en los ámbitos sociales, políticos, económicos, académicos y culturales. "El 
caracazo" en Venezuela, en febrero de 1989, la sublevación de los cocaleros y las reacciones contra la intención privatizadora del agua en Bolivia, así como las violentas manifestaciones en contra del "corralito" en Argentina en diciembre de 2001, son algunos de los eventos políticos y sociales más significativos de rechazo a las políticas neoliberales ocurridas a finales del siglo XX y en los albores del siglo actual en la región.

La consecuencia más determinante de estas reacciones al neoliberalismo fue la emergencia de gobiernos en Argentina, Brasil, Bolivia, Ecuador y Venezuela que capitalizaron este descontento y comenzaron a explorar otras formas de hacer política y, de manera especial, a implementar políticas públicas dirigidas a saldar la profunda deuda social a que condujo la aplicación del dogma neoclásico en América Latina, etapa conocida como la larga noche neoliberal, aludiendo a los efectos nefasto de estas políticas en la cotidianidad de todos los ciudadanos.

\section{POLÍTICAS PÚBLICAS ORIENTADAS A LOS SECTORES RURALESEN VENEZUELA: APROXIMACIÓN AL CONCEPTO DE RURALIDAD}

Las políticas públicas educativas en Venezuela contienen siempre la impronta del modelo económico bajo el cual se ejerce la gestión de gobierno en determinado período histórico. Y ese sistema económico ha estado, al menos, desde los inicios del siglo XX, marcado por la explotación y exportación del petróleo. Así mismo, la política agraria y toda la cultura campesina se trastocaron a partir de la evolución, durante los inicios del siglo XX, de la explotación de los productos del suelo a la explotación del subsuelo. ${ }^{4}$

Para hablar sobre la política educativa en los sectores rurales, es oportuno realizar un necesario preámbulo aclaratorio del concepto de ruralidad. La delimitación de lo rural no se plantea de manera sencilla y unívoca debido a que este término, significante de una práctica con connotaciones sociales en tensión y contradicción permanente, se formula a partir de otra realidad o contraparte: lo urbano. En muchos casos tal definición toma sus fuentes de los datos censales relativos a la población, la pobreza, empleo y educación en territorios campesinos o no urbanizados, la sujeción de este concepto a los datos censales de población ha conducido a definir lo rural por descarte de todo aquello que no es urbano.

Según reseñas de la CEPAL, ${ }^{5}$ las precisiones de lo rural han tendido a la caracterización de América Latina como un continente urbanizado, este hecho ha afectado el diseño y aplicación de políticas públicas, en tanto que se genera un sesgo anti rural en su concepción. 
En otros casos se delimita lo rural en función de la cantidad de la población. Por ejemplo, el Instituto Nacional de Estadísticas del Venezuela (INE) ${ }^{6}$ define lo rural en función de la densidad poblacional existente en un territorio determinado.

Romero, J. (2012), cuando explica la evolución de este término señala que una de las causas de dicho giro conceptual subyace en la comprobación de que las poblaciones de las áreas rurales cumplen funciones sociales que van mucho más allá de la producción y provisión de alimentos (ROMERO, 2012, p.p: 2). Esta perspectiva es interesante por cuanto expresa un elemento substancial de la vida en el sector rural. Se trata de una noción de ruralidad que alude a pueblos que construyen su identidad a partir de la estructuración de su vínculo con la tierra, vale decir, con el desarrollo de la vida en unión con la productividad.

Carvajal Ruíz, S.H. (2013) define el mundo rural desde un posicionamiento más antropológico, lo que nos permite analizar las dinámicas campesinas en correlación con el desarrollo de la vida, la historia y la cultura.

Esto que pretendemos (la ruralidad), ${ }^{7}$ significa la traducción de experiencias y
sensibilidades, saberes y conocimientos forjados al fragor de la faena campesina,
con sus luchas, logros; pero a su vez, como expresión de la denuncia por sus
condiciones de vida y las amenazas a ancestrales formas de organización social,
del trabajo y de su propia existencia; asimismo, esto implica recuperar esa vitalidad
orgánica, humana, con el medio natural, con sus esfuerzos e imaginarios, valores
y actitudes ante la vida, en experiencia sistemática de enseñanza y de aprendizajes.
Sobre todo, porque, en el nudo del asunto, se encuentra en el tema medular de la
tenencia de la tierra y los episodios y luchas asociadas a ésta, lo cual agrega a su
definición un argumento estrictamente político y económico; de tal manera que su
definición agrega aspectos vitales y de profundo calado estratégico. (CARVAJAL
RUÍZ, 2013. p. 8)

Con el avance de la industrialización, se produce en América Latina un giro en el modelo de desarrollo que provoca el desplazamiento de la inversión, tanto pública como privada, hacia los sectores urbanizados en detrimento de los sectores campesinos. La literatura sobre este tema plantea variadas concepciones sobre el desarrollo rural, una de ellas apunta a la modernización del campo como negación propia de su esencia para acercarse a las oportunidades que ofrecen los centros urbanos. Las reformas agrarias para el impulso de la agricultura han sido un punto clave en la materialización de un modelo de desarrollo que, en el caso de Venezuela, tiene varios puntos de inflexión definitorios. Pueden destacarse tres de ellos, por la utilidad que aportan en la comprensión de la aplicación de las políticas educativas que se 
despliegan en sectores rurales; el primero, lo representa la introducción de la explotación petrolera en los inicios del siglo XX como actividad económica sustitutiva del modelo latifundista agroexportador, el segundo se refiere a la profundización del neocolonialismo en las últimas décadas del siglo XX, el tercero se ubica en el siglo XXI con la introducción de un modelo económico suscrito en la doctrina antiimperialista y emancipadora bolivariana, el cual, muestra su primer punto de quiebre en la ley de tierras. Esta nueva ley tiene como finalidad romper con las formas tradicionales de tenencia y explotación de la tierra amparada en el concepto de soberanía productiva.

\section{LA POLÍTICA RURAL EN VENEZUELA}

En Venezuela la política rural es la que está orientada a la explotación de las áreas productivas en territorios agrícolas y pecuarios por excelencia, pero también se circunscriben las poblaciones pesqueras y mineras. Estos sectores están ubicados en territorios de una vasta extensión, pero de escasa población en comparación con la de las ciudades. En el caso de los territorios rurales de frontera, en su mayoría, están integrados por pueblos indígenas. Este último dato conlleva unas connotaciones importantes y particulares en términos de la rica y compleja actividad comercial (tanto reglamentada como ilícita) que se desarrolla en los territorios fronterizos con Colombia, Brasil y las Antillas.

El historiador venezolano Germán Carrera Damas explica: “...El siglo XIX es el tiempo bistórico más cargado en significados perdurables. De alli que el siglo XX no biciera más que mistificarlo." (Carrera Damas, 2011, pp.12). Esta idea ilustra de manera oportuna sobre la evolución histórica de la tenencia de la tierra y la pervivencia de una política con características neocoloniales del Estado venezolano durante el período posindependentista. La estructura agraria latifundista para entonces, de posesión de vastas extensiones concentradas en familias que en su mayoría eran de descendencia europea, representaba la derivación colonial del proceso de usurpación durante la invasión española de los siglos XV y XVI y, de reglamentación posteriormente, por parte de la corona, del despojo a los indígenas en los sucesivos siglos XVII y XVIII. Este acto de latrocinio se ejecutó a través de lo que se denominó composición de tierras. Así lo explica el historiador Orlando Araujo (2013):

A pesar de la voluminosa Legislación de Indias y de la preocupación formal que sus disposiciones agrarias denotan en favor del mantenimiento y respeto a la propiedad comunal indígena, lo cierto es que la concentración de las mejores tierras en pocas manos se debe más a la usurpación y ocupación de tierras 
comunales y "realengas" que a las "mercedes" concedidas por el poder real y que, estas "mercedes" o donaciones" lo eran como compensación de un acto violento, el de conquistar la tierra y someter al indio mediante el uso de la fuerza. (ARAUJO, 2013, p. 26-27)

Por su parte, F. Brito Figueroa (2009), explica que al mismo tiempo que la corona establece figuras jurídicas para favorecer la posesión por usurpación de la tierra, se va configurando una mano de obra representada "...por los esclavos en sentido absoluto y la población indigena y mestiza sometida a relaciones económico - sociales de servidumbre." (BRITO FIGUEROA, 2009, p. 76)

Durante los siglos XVIII y XIX se establece una aristocracia esclavista ${ }^{8}$ que estimula el modelo de producción agropecuaria basado en el latifundio y en la mano de obra esclava. Luego de la emancipación, en la segunda mitad del siglo XIX, la clase oligárquica conservadora, altamente terrófaga, fortalece el latifundio, estimula el comercio de mercancías debido a la relación de correspondencia de la producción agropecuaria con el mercado capitalista mundial (Ibídem, p. 289). Si bien, la libertad absoluta de los esclavos es decretada por Simón Bolívar en 1816, no es sino hasta 1854, cuando José Gregorio Monagas, para entonces presidente de la República, la pone en vigencia. Sin embargo, la liberación de los esclavos no supuso un avance en términos de autonomía y justicia social, sino que más bien, acentuó otro problema, el del trabajo servil.

El decreto de libertad para los esclavos, bajo el tiempo de los Monagas, es aparentemente un cambio en las relaciones de producción, pero en provecho de los dueños de la tierra para quienes resulta más ventajoso desprenderse de la familia esclava y utilizar solo los servicios de la mano de obra activa sujetándola a las relaciones típicas de la servidumbre feudal. La letra del decreto hace libres a los esclavos, pero la realidad social los hace siervos. (ARAUJO. 2013, p. 33)

El siglo XX es heredero de una Venezuela con un incipiente desarrollo urbanístico, pero que es eminentemente rural, con una estructura económica pre capitalista y mono productora agropecuaria (Brito Figueroa. 1984, p.p: 709). La larga dictadura de Juan Vicente Gómez (1908 a 1935) con la que abre el siglo XX establece un feroz sometimiento de las masas a través de la consigna orden, pazy trabajo. Sin embargo, el plan gomecista de modernización del campo es sorprendido con la aparición del petróleo. La dictadura gomecista genera una nueva burguesía que reemplaza la cultura de la europeización por una forastera norteamericana que establecerá en corto tiempo una nueva hegemonía, se trata de lo que el antropólogo Rodolfo Quintero (2014) ha denominado la cultura del petróleo. Ante el descubrimiento 
del petróleo, la agricultura pasó a ocupar un lugar secundario como actividad productiva y fuente de generación de riqueza. Pero, aun así, hay un aspecto importante destacado por Araujo, O. (2014) que tiene que ver con una forma de prevalencia de la cultura latifundista:

Para Gómez, el petróleo era un fruto de la tierra y su mentalidad de hacendado lo llevó a concebir la administración de esta riqueza con un criterio latifundista: otorgaba a sus amigos, familiares y partidarios, vastísimas concesiones de tierra y estos las traspasaban luego a las compañías extranjeras que explotaban las zonas petroleras. (ARAUJO, 2013, p. 37)

La cultura del petróleo se va desarrollando bajo la matriz del latifundio. Posterior a la larga dictadura de Juan Vicente Gómez, se renueva la lucha de los campesinos por la tierra. Los jóvenes que representaban una clase política intelectual recluida en las cárceles algunos y, en el exilio otros, una vez muerto el dictador, se organizan en estructuras políticas como base de la construcción de la democracia representativa. El segundo período dictatorial en Venezuela, lo instaura el General Marcos Pérez Jiménez hacia (1953 - 1958) y estuvo signado por el seguimiento y sujeción a las medidas de corte económico, político y social para la América Latina, provenientes de los planes desarrollistas propuestos desde las Naciones Unidas y avalados por los estudios de la CEPAL. Ya en 1960, se consuman estas medidas en el plan de desarrollo para América Latina denominado "Alianza para el Progreso", el cual incluía dentro de sus principales planeamientos las reformas agrarias. Es así como en tiempos del presidente de la República Rómulo Betancourt ${ }^{9}$ una vez extinguida la dictadura del General Marcos Pérez Jiménez y, electo presidente, se formula una reforma agraria en la que se destaca el reconocimiento a la propiedad privada sobre la tierra en menoscabo de las aspiraciones de justicia de las masas campesinas que retomaron la lucha por la recuperación de sus territorios ancestrales una vez extinguida la dictadura. Ello supuso un acto de traición a las masas campesinas que apoyaron el ascenso al poder de una clase política cuyas promesas reformistas presumían ya su oposición a poner bajo amenaza su legado burgués. De tal manera que en dicha ley se fortalece el predominio del latifundio:

En esa Ley de Reforma Agraria que allí se firma y con la cual estos señores consideran saldada su cuenta con las masas campesinas, no se proscribe el latifundio y en su artículo $2^{\circ}$ se "garantiza y regula el derecho de propiedad privada de la tierra, conforme al principio de la función social que la misma debe cumplir" (...) La Ley Agraria de 1960 es, en primer término, una ley para la burguesía agraria; en segundo término, una ley para revalorizar las tierras ociosas de propietarios absentistas y, 
en último término, una ley con algunas disposiciones reformistas en favor de los campesinos, disposiciones que no predominan sobre los otros dos aspectos y que no alcanzan a dar a dicha ley un carácter revolucionario. (Ibídem, p. 47)

La abundancia de divisas provenientes de la renta petrolera permitía encubrir la defectuosa política de producción agropecuaria y el siempre mediocre desarrollo industrial. Para solventar la necesidad de obtención de recursos para el sustento alimentario y de recursos industriales, se implementó la vía de las importaciones, hecho que profundizó la dependencia de los recursos del exterior y acunó la cultura del rentismo petrolero.

Si bien la explotación del petróleo constituyó una actividad económica de gran impacto, para el crecimiento del Producto Interno Bruto, mucho mayor fue el que generó en la configuración social y cultural de los venezolanos. R. Quintero (2014) lo define muy bien en su obra Antropología del Petróleo.

Los monopolios internacionales del petróleo cuya intervención en la dinámica de la sociedad venezolana produce, en el transcurso de unas décadas transformaciones insospechadas en siglos de historia nacional, forman en lo político, lo económico y lo sociocultural un poderoso imperio que determina estilos de vida y niveles de existencia de millones de personas, y asegura ganancias fabulosas a los emperadores y sus colaboradores principales. (QUINTERO, 2014, p. 89)

La nueva colonización a partir de la explotación petrolera constituyó un giro crucial en los marcos de interpretación de la realidad y de relacionamiento social venezolanos. El autor antes citado plantea que la penetración de la cultura del petróleo constituyó una civilización de conquista que desdibujó los rastros de la cultura colonial europea. La nueva cultura se refleja en los patrones de convivencia y en el cuerpo de valores necesarios para orientar las formas de proceder en el contexto social.

Entre los rasgos del estilo de vida propios de la cultura del petróleo predomina el sentido de dependencia y marginalidad. Los más "transculturados” llegan a sentirse extranjeros en su país, tienden a imitar lo extraño y subestimar lo nacional. Piensan a la manera "petrolera" y para comunicarse con los demás manejan el "vocabulario del petróleo". La cultura del petróleo es una cultura de conquista, que establece normas y crea una nueva filosofía de la vida, para adecuar una sociedad a la necesidad de mantenerla en las condiciones de fuente productora de materias primas.

Expresión de la cultura del petróleo en el territorio venezolano son las construcciones verticales y los edificios de departamentos, aunque no sean necesarios, porque hay terreno suficiente. Pero imitan a los rascacielos. (QUINTERO, 2012, p. 19) 
Cabe destacar que la historia de la Venezuela del siglo XX lleva la huella de la implantación de un proceso de nuevo coloniaje acometido por los grandes monopolios y oligopolios petroleros de países europeos y especialmente de Estados Unidos. En este siglo se va conformando una cultura rentística extractivista, se profundiza la dependencia, el subdesarrollo, el crecimiento demográfico en los sectores urbanos, la disminución de la población rural debido a la desinversión en la producción agrícola y pecuaria, en su lugar, el crecimiento de una burguesía latifundista, la aparición y consolidación de una burguesía petrolera y comercial.

La idea de progreso que trasciende de la labranza al balancín ${ }^{10}$ generó un complejo entramado de valores y modelos sociales de actuación legitimados a partir de la idea de un progreso que se consideraba en confrontación con los valores autóctonos. El abandono del campo para poblar las ciudades introduce hábitos laborales diferentes a los tradicionales de los sectores rurales. Además de ello, la industria petrolera genera una estratificación de clases sociales dentro de las cuales destacan argumentos ocupacionales y raciales imbricados en un sistema de valores que establece, no solo los límites de cada clase, sino que traza las aspiraciones de ascenso social. Ahora bien, lo que destaca a lo largo del desarrollo de la cultura del petróleo es la configuración de una clase capitalista representada por los jefes de la industria petrolera que proceden de las compañías de extracción de petróleo extranjeras y una clase obrera integrada por los trabajadores que llegan a los campos petroleros en condición de desplazados del campo en busca de mejores condiciones de vida. El campo petrolero es una categoría y una realidad social única y nueva, no es el campo, tampoco la ciudad y, por consiguiente, genera una realidad que no solo sorprende al nativo, sino que lo envuelve, lo colma, lo desalma, lo deshace y lo recicla en una suerte de personaje sin identidad, incapaz de reencontrarse con su esencia nuevamente.

\footnotetext{
El campo petrolero no es una ciudad, tampoco una aldea. Es una plantación industrial, un sistema socioeconómico incrustado en la sociedad nacional como efecto del colonialismo moderno. Un centro de población sui géneris, una categoría demográfica propia de países dependientes. Muy mecanizado; un medio adecuado para que predominen las relaciones capitalistas. (Ibídem, p. 30)
}

Desde el plano cultural, la estructuración de los valores sociales de un capitalismo degradado genera una clase social desenraizada de sus valores idiosincráticos. R. Quintero (2012), los caracteriza como “(...) 'bombres Creole' y 'hombres Shell', nacidos en el territorio venezolano pero que piensan y viven como extranjeros; hombres de las compañias y para las compañias, personas antinacionales." (Ibídem. 2012, p. 39) 
Lograr una delimitación del estado de la educación rural en Venezuela en los actuales momentos, resultaría incompleto e insubstancial si no se enmarca en un contexto histórico de conformación de clases sociales afectadas por la nueva colonización norteamericana a partir de la explotación petrolera del siglo XX. De manera que todo este preámbulo es necesario para comprender un proceso histórico que fue conformando los marcos que sirvieron de encuadre para comprender y asumirse como ciudadanos en un país que, a la vez que se necesita, se rechaza por no ser el norte floreciente y desarrollado.

\section{LA EDUCACIÓN SUBORDINADA A LA CULTURA DEL PETRÓLEO}

Hasta finales de los 1960, el viejo sistema escolar, con sus arcaicas estructuras y concepciones originadas de la reforma educativa de 1955, espera por los cambios que el nuevo modelo de crecimiento económico y de desarrollo industrial requería para ese momento. Durante las décadas del bipartidismo democrático, ${ }^{11}$ los gobiernos del partido social demócrata Acción Democrática (AD) y, el partido social cristiano Copei; se proponen la transformación de Venezuela en una sociedad moderna, a través de un proyecto desarrollista industrial que contemplaba la reafirmación de la explotación petrolera, minera y la modernización del campo. La reforma educativa para el logro de los objetivos de desarrollo económico se propone como un aspecto fundamental, ya que había que garantizar la formación del recurso humano que se demandaba para alcanzarlo.

Entre los aspectos innovadores de este período se menciona la creación en 1959 del Instituto de Cooperación Educativa (INCE), se trata de un proyecto redactado por el maestro Luis B. Prieto Figueroa, con la finalidad de crear una institución de formación técnica con una representación tripartita, conformada por el Estado, las empresas y los trabajadores, de esta manera se podía contribuir con la formación de la clase trabajadora y con la de los jóvenes que estaban en situación de desempleo.

La creación de institutos de formación docente, del Reglamento para las Escuelas de Artes Plásticas y Artes Aplicadas, constituyeron otros aspectos importantes para alcanzar el adiestramiento de una mano de obra técnica calificada que el plan de desarrollo industrial exigía con urgencia.

Para el año 1961 se promulga la nueva Constitución Nacional de la República de Venezuela (CNRV) y se establece dentro del Capítulo II, en el artículo 55 la educación como un deber: "La educación 
es obligatoria en el grado y condiciones que fije la ley. Los padres y representantes son responsables del cumplimiento de este deber, y el Estado proveerá los medios para que todos puedan cumplirlo.” (p. 12)

Así mismo se establece en el Capítulo IV de los Derechos Sociales, artículo $\mathrm{N}^{\mathrm{o}} 78$, la educación como un derecho social:

Todos tienen derecho a la educación. El Estado creará y sostendrá escuelas, instituciones y servicios suficientemente dotados para asegurar el acceso a la educación y a la cultura, sin más limitaciones que las derivadas de la vocación y de las aptitudes.

La educación impartida por los institutos oficiales será gratuita en todos sus ciclos. Sin embargo, la ley podrá establecer excepciones respecto de la enseñanza superior y especial, cuando se trate de personas provistas de medios de fortuna. (Ibídem, p. 16)

En este mismo orden de ideas, se expresa en el artículo $\mathrm{N}^{\circ} 80$, los fines de la educación:

La educación tendrá como finalidad el pleno desarrollo de la personalidad, la formación de ciudadanos aptos para la vida y para el ejercicio de la democracia, el fomento de la cultura y el desarrollo del espíritu de solidaridad humana. El Estado orientará y organizará el sistema educativo para lograr el cumplimiento de los fines aquí señalados. (Ídem)

De la misma manera que las políticas agrarias se asumen bajo los parámetros de un conservadurismo que perpetúa el latifundismo, las políticas educativas, pese al avance que suponen en términos del derecho a la educación y al fortalecimiento del Estado Docente, soslayan la discusión sobre la necesidad de una transformación en las formas de tenencia la tierra.

\section{LO RURAL Y LO CAMPESINO EN LA EDUCACIÓN RURAL EN VENEZUELA}

Las palabras, los conceptos y constructos teóricos son tributarios a sus contextos, al espíritu de la época, a las ideas fuerzas que en un momento histórico determinado gobiernan la cotidianidad, así como las racionalidades discursivas y explicativas de una realidad concreta. Tal es el caso del constructo Educación Rural en el proceso histórico - social y educativo de Venezuela.

Para explicitar este asunto cabe, brevemente, señalar dos hitos fundamentales. El primero de ellos fundamentado en la decisión del entonces ministro de Educación Nacional del gobierno Gomecista, Rafael González, de crear en marzo de 1932 los primeros programas de Educación Rural. Para diciembre de ese mismo año, el ministerio 
ordena la creación de las primeras escuelas rurales mixtas (Podían asistir indistintamente niñas y niños). Es así como desde sus orígenes es asumida la denominación de "Educación Rural" para definir este espacio pedagógico; idea ésta sobre la cual se harán, más adelante algunas reflexiones que explican su sentido y alcances políticos y pedagógico.

El contexto en el cual se fundamenta esta decisión en la política educativa dirigida a fomentar la educación rural en el país, tiene como característica destacable que el $67 \%$ de la población venezolana habitaba y trabajaba en el espacio rural - agrario, es decir era campesina. A este panorama se sumaba unas condiciones de atraso cultural reflejadas en las altas tasas de analfabetismo, una población campesina diezmada por enfermedades tropicales como el paludismo y la malaria. Venezuela comenzaba así el complejo tránsito de una sociedad agraria - campesina hacia otra petrolera y urbana.

El otro referente importante lo constituye la obra del pedagogo venezolano Luís Padrino, uno de los precursores de la Educación Rural, dedicado tanto, a la enseñanza, como a la reflexión teórica - política y pedagógica en la escuela rural. El maestro Padrino tuvo en su pasantía en México, concretamente en Ayotzinapa, en el contexto de desarrollo de las Escuelas Normales Rurales Mexicanas una de sus experiencias vitales. Este hecho representó una influencia determinante para su formación intelectual y profesional que luego, trasladó al magisterio venezolano. El reconocimiento a la importancia de las Escuelas Normales Rurales Mexicanas se muestra en la siguiente afirmación:

“...nacieron con el deseo de incorporar al campesino mexicano a la cultura nacional; por el anhelo de homogeneizar la nación mexicana, en cuanto a idioma, cultura y mejores formas de vida cívica dentro de la sociedad en la cual vive, de la que forma parte y de la que constituye su nervio vital."12

La Educación Rural en el contexto venezolano contenía una orientación modernizadora urbanística que hegemonizaba para entonces el discurso y la práctica política, así una de sus finalidades era la de convertirse en un vehículo para la "civilización" del campesinado. En este sentido, Luque (2013) al parafrasear al maestro Luis Padrino sostiene:

"El fin que persigue la Escuela Rural no es, como muchos lo han preconizado, el adscribir al niño campesino a la vida del campo, sino incorporarlo a la cultura nacional; puesto que ella trata de fomentar y crear en nuestro campesino una conciencia colectiva de acuerdo con las circunstancias y problemas del lugar." ${ }^{\prime 3}$

Estos aportes son determinantes para el decurso de la evolución intelectual y política de la Educación Rural, en su concepción, 
finalidades y praxis en el tejido socio - cultural venezolano. Aunque en el discurso político - educativo se reconoce la necesaria recuperación de las experiencias y la vida en el campo, este ámbito de la educación se percibe en una relación asimétrica, en desventaja respecto al ideal de vida moderno ofrecido por la industrialización y su correlato cívico - demográfico, el urbanismo.

\section{POLIITICA EDUCACIONALEN BRASIL:DE LA EDUCACIÓN RURAL A LA EDUCACIÓN DEL CAMPO}

Para comprender las políticas del Estado brasilero respecto al espacio campesino, es necesario realizar algunas acotaciones históricas. Brasil, al igual que el resto de los países que hoy conforman el continente americano sufrió las consecuencias del colonialismo; en el caso particular brasilero, la llegada de los portugueses en el siglo XVI, trajo consigo la imposición del modelo de educación cristiana impulsado por los sacerdotes jesuitas. El religioso, constituyó uno de los factores de mayor influencia cultural de los pueblos indígenas, percibidos éstos por los colonialistas como inferiores. Este hecho se expresó en los procesos de transculturación y reproducción de la cultura colonizadora.

Desde ese período hasta la actualidad, Brasil ha sido un país que reproduce métodos educacionales europeos y estadounidenses, uno de los ejemplos más notorios se expresa en la translación Francia del Ciclo de Formación, método éste surgido en 1936, e implementado en Brasil en escuelas del campo y de la ciudad de varios estados durante la década de 1990. Los fundamentos de este programa parten de las orientaciones neoliberales del Banco Mundial como propuesta educativa para los países latinoamericanos.

Otro programa que surge con ese mismo propósito, pero en este caso, pensado exclusivamente para el campo, fue el Programa Escuela Activa. El referido Programa fue pensado a partir de los presupuestos de la Escuela Nueva, ${ }^{14}$ la cual, criticaba el sistema tradicional de educación e influenció varias legislaciones posteriores.

Cabe señalar que el Programa Escuela Activa fue implementado en Colombia en la década de 1970, en las denominadas escuelas multiseriadas del campo con el objetivo de reducir los índices de analfabetismo, utilizando la nomenclatura de Programa Escuela Nueva. Según el Boletín de Educación de OREALC - (Oficina Regional de Educación para América Latina y Caribe) de julio diciembre de 1968, dicho programa fue desarrollado además en doce países latinoamericanos. 
En Brasil, el Programa Escuela Activa empezó a implementarse en 1997, según lo establece el documento "Directrices para la Implantación e Implementación de la Estrategia Metodológica Escuela Activa" (BRASIL, 2010) organizado por MEC/FNDE/ FUNDESCOLA, en mayo de 1996,

[...] um grupo de técnicos da Direção-Geral do Projeto Nordeste (Projeto Educação Básica para o Nordeste), projeto do Ministério da Educação, e técnicos dos estados de Minas Gerais e Maranhão foram convidados pelo Banco Mundial a participarem, na Colômbia, de um curso sobre a estratégia "Escuela NuevaEscuela Activa", desenhada por um grupo de educadores colombianos que, há mais de 20 anos, atuavam com classes multisseriadas daquele país. Surgiu daí a proposta de implantar essa estratégia metodológica a fim de auxiliar o trabalho do educador com classes multisseriadas brasileiras. Em agosto de 1996, em um seminário ministrado por um representante da Fundación volvamos a la gente, responsável na Colômbia pela implantação e implementação da estratégia no Brasil, a DGPN-Direção-Geral do Projeto Nordeste reuniu em Brasília todos os Secretários de Educação e diretores de ensino dos estados do Nordeste para conhecerem a estratégia e decidirem sobre sua adoção (BRASIL, 2010a).

Así, en 1997 el Programa Escuela Activa se formalizó en Brasil con financiamiento del Banco Mundial, inicialmente en la Región Nordeste, cuya asistencia técnica y financiera surgió del Proyecto Nordeste/MEC. En 1999, finalizado el Proyecto Nordeste, el Programa Escuela Activa fue incluido en el Programa Fondo de Fortalecimiento de la Escuela - FUNDESCOLA, y se expandió en varios estados del territorio nacional.

Para el 2007, fue transferido a la Secretaría de Educación Continuada, Alfabetización y Diversidad - SECAD/MEC, bajo la responsabilidad de la Coordinación - General de Educación del Campo. Finalmente en 2012, fue sustituido por el Programa Escuela de la Tierra, con un cambio sustantivo en el énfasis de la concepción pedagógica asumida. En este sentido, mientras el primero surge fundamentado en los presupuestos teórico - metodológicos de la Escuela Nueva, con base epistemológica fundamentada en Piaget, el segundo tiene sus cimientos en el materialismo histórico dialéctico y se apoya en Vigotsky (Idem).

\section{DE LA EDUCACIÓN RURAL A LA EDUCACIÓN DEL CAMPO}

Si bien en Venezuela se utiliza el término "Educación Rural" para referirse a las enseñanzas formales dirigidas en los sectores campesinos; en Brasil, actualmente ese término tiene una connotación conservadora; en este se comprende que en la Educación Rural predominan los intereses capitalistas de los empresarios del agronegocio, del asistencialismo y del control político del Estado. 
En cambio, la Educación del Campo es una noción que surgió de la lucha de los movimientos sociales del campo en contra del agronegocio, mediante la cual existe una valoración de la cultura, de la identidad y de los saberes del campesino entendido como sujeto protagonista de su historia. Empero, la principal diferencia con respecto a la noción de ruralidad está relacionada con el modo de producción y el modo de existencia. La Educación del Campo tiene en cuenta el trabajo del hombre campesino como clase trabajadora, en su condición de oposición al agronegocio como práctica de una clase poseedora de los medios de producción (SANTOS, 2016).

La Educación del Campo tuvo su marco inicial en 1997, en el I Encuentro Nacional de Educación en la Reforma Agraria (I ENERA), así como en las Conferencias Nacionales de Educación del Campo, realizadas posteriormente al I ENERA. En la legislación brasileña la Educación del Campo surge desde 2002 con la aprobación de la Resolución CNE/CEB N N $^{\circ} 01$ del 03 de abril, documento en el cual se instituyeron las Directrices Operacionales de la Educación del Campo. Según Caldart (2002), "la perspectiva de la Educación del Campo es exactamente la de educar este pueblo, estas personas que trabajan en el campo, para que se articulen, se organicen y asuman la condición de sujetos de la dirección de su destino".

Históricamente, la educación pensada para el contexto rural surge por primera vez en la legislación brasileña en la Constitución Federal de 1934, bajo la denominación de Educación Rural, la cual subraya en el Artículo 121, párrafo $4^{\circ}$, que:

O trabalho agrícola será objeto de regulamentação especial em que se atenderá, quanto possível, ao disposto nesse artigo. Procurar-se-á fixar o homem ao campo, cuidar de sua educação rural, e assegurar ao trabalhador nacional a preferência na colonização e aproveitamento das terras pública (BRASIL, 1934).

Este mismo texto constitucional, en el Artículo 156, párrafo único, resalta que: "Para la realización de la enseñanza en las zonas rurales, la Unión reservará, como minimo, 20\% de las cuotas destinadas a la educación en el respectivo presupuesto anual' (BRASIL, 1934). A pesar de no ser mencionada en la Constitución de 1937, la Educación Rural reaparece en el texto constitucional de 1946, en el cual se expresa que el Estado traslada su responsabilidad a empresas agrícolas, definiendo que estas deberían asegurar la enseñanza primaria y gratuita para los trabajadores y sus hijos.

Con la Constitución de 1967, se inaugura un período de muchas dificultades para la democratización y calidad de la educación por cuanto la dictadura militar lanzó proyectos para eliminar el analfabetismo. En el mismo proceso político, fue aprobada la Ley 
de Directrices y Bases no 5.692/71, que no menciona en ningún pasaje la población rural como grupo de identidad y con formativas necesidades específicas.

En la Constitución de 1988, la educación alcanzó una significación importante; sin embargo, se mantuvo la denominación y el tratamiento de Educación Rural aquella dirigida para los pueblos y sectores campesinos, pero dado su carácter democrático surge, con base en esta Constitución, la Ley de Directrices y Bases de la Educación Nacional, LDB no 9.394/96 (artigos 23, 26 e 28), que además de garantizar varios derechos a los campesinos, abre el panorama para la incorporación de la emergente concepción de Educación del Campo como modalidad de enseñanza.

No obstante, es a partir de la segunda mitad de la década de 1990, cuando se agrega a la legislación brasileña un cuerpo de resoluciones, pareceres y decretos, específicamente para garantizar los derechos de los campesinos, fruto de las diversas luchas de los movimientos sociales y de la clase trabajadora en el campo. Desde el punto de vista legal, son reconocidos como pueblos del campo:

Art. $1^{\circ}-\mathrm{I}-[\ldots]$ os agricultores familiares, os extrativistas, os pescadores artesanais, os ribeirinhos, os assentados e acampados da reforma agrária, os trabalhadores assalariados rurais, os quilombolas, os caiçaras, os povos da floresta, os caboclos e outros que produzam suas condições materiais de existência a partir do trabalho no meio rural; (BRAIL, 2010b).

A partir de estos avances en las políticas educativas, existe un acuerdo entre los movimientos sociales y los investigadores sobre la diferenciación entre los términos Educación Rural y Educación de Campo ello obedece a criterios de contextualización de cada una de las experiencias educativas, a partir de realidades político, históricas y culturales. Por lo tanto, no se trata de en un cambio de nomenclatura vacía, sino en la construcción de una comprensión de una educación situada para los pueblos del campo, de tal manera que la denominación "educación rural" fue entendido desde sus incios en contextos concretos de América Latina (México, Venezuela, entre otras realidades) como un tipo de educación apegadas a la idea de "progreso de las sociedades", que tenía un sentido "civilizatorio urbano"; sin embargo, con el paso de los años ella, como praxis social y cultural compleja, se ha ido reconfigurando en estos contextos y, de acuerdo con los propósitos emancipatorios de su origen en los movimientos sociales, difiere en que no tiene la intención de formar los sujetos para abandonar el campo, destruir los recursos naturales y tratar la naturaleza como materia prima solo para la extracción de lucro. En este sentido, Molina y Fernandes señalan que mientras 
La Educación del Campo ha sido creada por la población rural, la educación rural es el resultado de un proyecto creado para la población campesina, de manera que los paradigmas proyectan diferentes territorios. Dos diferencias básicas de estos paradigmas son los espacios donde se construyen sus protagonistas. Por estas razones, reafirmamos la Educación Rural como un nuevo paradigma que han construido estos grupos sociales y que rompe con el paradigma de la educación rural, cuya referencia es el productivismo, es decir, el campo solo como un lugar para la producción de mercancías y no como el espacio vital (FERNANDES; MOLINA, 2004, p. 63).

Cabe resaltar que la clase trabajadora en el campo continúa teniendo innumerables desafíos; sin embargo, no puede dejar de significarse algunas conquistas políticas en el ámbito educativo, a saber: la Resolución CNE/CEB n ${ }^{\circ}$ 1/2002 que instituye las Directrices Operacionales para la Educación del Campo; Parecer CNE/CEB n ${ }^{\circ}$ 1/2006 que reconoce los Días Lectivos de la Alternancia; Resolución CNE/CEB n 4/2010 que reconoce la Educación del Campo como modalidad específica y define la identidad de la escuela del campo; Decreto $\mathrm{n}^{0} 7.352$, de 4 de noviembre de 2010, que dispone acerca de la Política Nacional de Educación del Campo y sobre el Programa Nacional de Educación en la Reforma Agraria (PRONERA); Resolución CNE/CEB no 2, de 28 de abril de 2008, que establece directrices complementarias, normas y principios hacia el desarrollo de políticas públicas de asistencia de la Educación Básica del Campo; Ley $\mathrm{n}^{\circ} 12.960$, de 27 de marzo de 2014, que dispone sobre la manifestación del órgano normativo del sistema de enseñanza para el cierre de escuelas del campo, indígenas y quilombolas; Decreto MEC $n^{\circ} 86$, de $1^{\circ}$ de febrero de 2013, que instituyó el Programa Nacional de Educación del Campo - Pronacampo, entre otras.

Un hito importante en la legislación, es el que hace alusión a las garantías de las políticas educacionales orientadas a la población campesina, de acuerdo a lo observado en el Art. $1^{\circ} \int 4^{\circ}$ del Decreto 7.352/2010:

A educação do campo concretizar-se-á mediante a oferta de formação inicial e continuada de profissionais da educação, a garantia de condições de infraestrutura e transporte escolar, bem como de materiais e livros didáticos, equipamentos, laboratórios, biblioteca e áreas de lazer e desporto adequados ao projeto políticopedagógico e em conformidade com a realidade local e a diversidade das populações do campo (BRASIL, 2010).

En ese sentido, durante la última década fue posible observar la implementación de varios programas educacionales en el país, por ejemplo: Escuela Activa, Escuela de la Tierra, Programa Nacional del Transporte Escolar - PNATE, Programa Nacional para Alimentación Escolar - PNAE, Programa Nacional del Libro Didáctico - PNLD 
Campo, Projoven Campo Saberes de la Tierra, además de otros (SANTOS; CARDOSO; OLIVEIRA, 2017). Resaltamos que uno de los más grandes desafíos en la actualidad lo representa la lucha por el mantenimiento de los derechos de los campesinos, dado que el gobierno brasileño actual tiene priorizado los intereses capitalistas, con atención a los empresarios del agronegocio en el campo, los cuales, han invertido en educación pero en la perspectiva conservadora de la Educación Rural.

\section{CONSIDERACIONES FINALES}

Los cambios ocurridos en el capitalismo global han provocado transformaciones que cambiaron la forma de concebir y gestionar las políticas públicas y la relación de los Estados hacia la sociedad en general, para adaptarse al nuevo orden mundial de carácter neoliberal, establecido por los países centrales a partir de la crisis del Estado del Bienestar.

Estas reformas ocurridas en el contexto global impactaron en la región latinoamericana, obligada a reconfigurar su forma de gestión, debido a su adscripción a un modelo basado en la racionalidad técnica weberiana, y es a partir de la década de 1980, cuando estableció un nuevo pacto federativo fundamentado en la colaboración entre los entes federados, cuyo modelo gerencial, inspirado en la iniciativa privada, pasó a la lógica basada en la regulación estatal, con metas establecidas para alcanzar mayor productividad y eficiencia, con el fin de atender a la exigencias de las agencias multilaterales.

En las políticas educacionales, esas directrices llegaron acompañadas de un discurso ideológico naturalizado, a través del cual, se creyó en la necesidad de modernizar para mejorar la calidad de la educación básica. Al asumir estos preceptos neoliberales, la política estatal adhirió a la lógica del mercado propuesta por el Banco Mundial y por la Organización para la Cooperación y el Desarrollo Económicos (OCDE), que pregonan una gestión educacional enfocada en los resultados y en los índices de rendimiento, asuntos éstos que fueron incorporados en la planificación de las políticas de la educación del campo y de la ciudad.

En la educación para de la población campesina, concebida como Educación del Campo en el contexto brasilero, y como Educación Rural en Venezuela, se observa el predominio de los intereses mercantilistas de las transnacionales del agronegocio. En Brasil, las políticas sociales caminan hacia la privatización y el alejamiento del Estado en su función de garante, regulador y evaluador de este ámbito de la educación pública. A pesar de las variadas conquistas legislativas, los campesinos encuentran muchas 
dificultades para hacer que sus derechos evoluciones del aspecto meramente formal y se materialicen en hechos.

Respecto a Venezuela, pervive aún la huella de la implantación de un proceso de nuevo coloniaje acometido durante el siglo XX, por los grandes monopolios y oligopolios petroleros liderado por transnacionales estadounidenses y europeas. Con el fortalecimiento de la actividad rentística extractivista, se profundizó la dependencia, el subdesarrollo, el crecimiento demográfico descontrolado en los sectores urbanos; esto trajo consigo la disminución de la población campesina provocado por la desinversión en la producción agrícola y pecuaria; esta complejidad de fenómenos políticos, sociales económicos y culturales se expresa en el reflujo de la otrora burguesía latifundista, y la emergencia y consolidación de otra, con un perfil vinculado al aprovechamiento de la renta petrolera y comercial.

De la misma manera que las políticas agrarias se asumen bajo los parámetros de un conservadurismo que perpetúa el latifundismo, las políticas educativas, pese al avance que suponen en términos del derecho a la educación y al fortalecimiento del Estado Docente, soslayan la discusión sobre la necesidad de una transformación en las formas de tenencia la tierra.

De allí que el giro que el nuevo modelo de desarrollo contemplado en el cuerpo doctrinario constitucional - legislativo y en los planes económicos para el desarrollo nacional, que aspiran la construcción del Estado Comunal, con un marcado acento socialista y antiimperialista promovido en las últimas dos décadas, contienen los soportes para el desarrollo armónico de la sociedad integral e integrada, y a esta la vida y quehaceres de los sectores campesinos que apuntale la ruptura con el viejo orden liberal burgués.

Ahora bien, la función de la educación en los ámbitos campesinos tiene una importancia de primer orden en la orientación de una nueva cultura que, lejos de fusionarse con modelos reformistas foráneos, se asuma al margen de la lógica mercantilista propia del capitalismo. Se trata de irradiar una nueva espiritualidad que recupere la historia y la identidad cultural capaz de reconstruir el talante colectivo y fecundo de la convivencia comunitaria. En la actualidad las experiencias de la clase campesina trabajadora en Brasil y Venezuela, caracterizadas por posiciones contra - hegemónicas en la correlación de fuerzas que se establecen entre el capital y el trabajo, encajan perfectamente en lo que algunos historiadores y antropólogos denominan una cartografía de la resistencia. 


\section{REFERENCIAS}

ARAUJO, Orlando. Venezuela violenta. (C. V. petróleo, Ed.) Caracas, Venezuela: Banco Central de Venezuela, 2013.

BRASIL. Constituição da República Federativa do Brasil. Brasília, DF: Senado, 1988.

BRASIL. Lei de Diretrizes e Bases da Educação Nacional. Lei n. 9.394/96. Brasília, 1996.

BRASIL. Diretrizes Operacionais para a Educação Básica nas Escolas do Campo. Resolução CNE/CEB n. 1, de 03 de abril de 2002. Brasília, 2002.

BRASIL. Parecer CNE/CEB n. 1/2006. Dias Letivos para a aplicação da Alternância nos Centros Familiares de Formação por Alternância. Brasília, 2006.

BRASIL. CONSELHO NACIONAL DE EDUCAÇÃO. Diretrizes complementares, normas e princípios para o desenvolvimento de políticas públicas de atendimento da Educação Básica do Campo. Resolução Complementar CNE/CEB No 2, de 2008.

BRASIL. Projeto base/ - Brasília: Ministério da Educação, Secretaria de Educação Continuada, Alfabetização e Diversidade, 2010a. (Programa Escola Ativa)

BRASIL. Decreto n. 7.352 de 4 de novembro de 2010. Institui o Programa Nacional de Educação na Reforma Agrária. Brasília, 2010b.

BRASIL. Lei De Diretrizes e Bases da Educação Nacional. Lei Nº 5.692/72.

BRASIL. Constituição Federal de 1934. Diário Oficial de 16 de julho de 1934. Brasília, 1934. Disponível em: http://www.planalto.gov.br/ccivil_03/constituicao/constituicao34. htm Acesso em: 27 jan. 2018.

BRITO FIGUEROA, Federico. Historia económica y social de Venezuela. 5ta. Ed. Caracas, Venezuela: Ediciones de la Biblioteca - EBUC, 2009.

CALDART, Roseli Salete. Por uma educação do campo: traços de uma identidade em construção. Petrópolis: Vozes, 2002.

CARVAJAL RUÍZ, Samuel. Hilcías. Apuntes sobre la educación rural en Venezuela. Ponencia. Material Mimeografiado. Bahía, Brasil, 2013.

CARRERA DAMAS, Germán. Venezuela: proyecto nacional y poder social. $1^{a}$ Ed. Mérida, Venezuela: Universidad de los Andes, 2011. Obtenido de www2.ula.ve/ publicacionesacademico.

Constitución de la República de Venezuela. Congreso Nacional de la República. Caracas, Venezuela, 1961.

FERNANDES, Bernardo Mançano, MOLINA, Mônica Castagna. O Campo da Educação do Campo. In: Por uma educação básica no campo: Contribuições para a construção de um projeto de Educação do Campo. V. 5. Brasília, 2004, p.53-80.

KLEIN, Naomi. La doctrina del Shock: el auge del capitalismo del desastre. Barcelona: Planeta, 2012. 
LUQUE, Guillermo. Luis Padrino: Maestro de la Escuela Nueva y fundador de la Educación Rural en Venezuela. Caracas: Fondo Editorial de la Facultad de Humanidades y Educación y Fundación Nacional de la Historia, 2013.

LUQUE, Guillermo. Luis Padrino: Fundador de la Educación Rural en Venezuela. Revista de Historia de la Educación. Enero - Diciembre, N.16, pp. 138 - 151, 2013.

PERONI, Vera. M. A privatição do público: implicações para a democratização da educação. Brasilia: Liber Libro, 1013.

PUIGGRÓS, Adriana. Educación neoliberal y quiebre educativo. Nueva Sociedad, 146, 90-101, Noviembre/Diciembre, de 1996.

QUINTERO, Rodolfo. Antropología del petróleo. Caracas, Venezuela: Banco Central de Venezuela, 2012.

ROMERO, Juan. Lo rural y la ruralidad en América Latina: categorías conceptuales en debate. Psicoperpectivas. Individuo y Sociedad, 11(1), 8-31, 2012. Recuperado el 16 de Julio de 2017.

SANTOS, Arlete Ramos dos. Aliança (neo) desenvolvimentista e decadência ideológica no campo: movimentos sociais e reforma agrária do consenso. Curitiba: CRV, 2016.

SANTOS, Arlete Ramos dos.; CARDOSO, Elisângela Moreira Cardoso.; OLIVEIRA, Niltânia Brito. Os impactos do PAR nos municípios de Vitória da Conquista, Ilhéus e Itabuna (2013 - 2017). Revista Práxis Educacional, Vitória da Conquista, v. 13, n. 26, p. 110139, set./dez. 2017. Disponible en: http://periodicos2.uesb.br/index.php/praxis/article/ view/2823. Acessado em: 12 de nov. de 2018.

\section{NOTAS}

1 Entre otras, se mencionan: la atención de las necesidades básicas de los pueblos en educación, salud y trabajo.

2 Se plantea la matriz de la poca o nula "productividad" y "rentabilidad" de las empresas públicas y la búsqueda de la "eficiencia".

3 Uno de los textos clásicos de Hayek en el que desarrolla esta tesis es el libro "Camino de servidumbre", 1944.

4 La frase "del suelo al subsuelo" constituye un subcapítulo de la obra Venezuela Violenta del historiador Orlando Araujo (2013). Texto prolijo en razonamientos para ilustrar la evolución del modelo agroexportador al modelo de explotación de hidrocarburos.

5 CEPAL, 2017. Panorama multidimensional del desarrollo urbano en América Latina y el Caribe.

6 Documento web: Definición de población urbana y rural utilizadas en los censos de los países latinoamericanos. https://www.cepal.org/publicaciones/xml/0/5160/BD63def00e.html.

7 La aclaración entre paréntesis es nuestra.

8 Orlando Araujo (2013), explica cómo luego de las luchas independentistas se conforma 
una burguesía terrateniente comercial que se ampara en la creación de una serie de bases jurídicas para preservar la esclavitud y legalizar la usura y la usurpación de tierras. Utiliza, como categoría para describir a esta clase social altamente mercantilista, el término traído de la literatura europea por el reconocido historiador Carlos Irazábal para el caso venezolano, de aristocracia esclavista.

9 Presidente provisional de Venezuela en el período 1945 - 1948, tras la deposición a través de un golpe político - militar del presidente Isaías Medina Angarita y, presidente electo en el período 1959 - 1964.

10 Se ha querido hacer una paráfrasis del texto de Quintero en el que plantea: 'La torre petrolera hoy, como el arado de madera traído por los españoles en el pasado, simboliza transformaciones de la cultura material de los venezolanos. Abora, como entonces, la utilización del progreso técnico como instrumento de conquista, lejos de impulsar el progreso social, lo detiene y lo deforma." (Ibídem, p. 25).

11 En Venezuela, se denomina bipartidismo democrático al período que va desde 1958 hasta 1998. Se caracterizó por el establecimiento de una alianza, luego de derrotada la dictadura perezjimenista, para la alternancia del poder de los dos partidos hegemónicos AD y Copei (excluyendo a los partidos de izquierda), con el respaldo de Fedecámaras, organización empresarial que constituyó el enlace y nervio de dicha alianza con el plan neocolonial estadounidense. Este proceso histórico ha sido estudiado de manera prolija por el historiador Mario Sanoja Obediente, en su obra: "Historia Sociocultural de la Economía Venezolana”. BCV. Caracas. 2011.

12 Citado por Luque, G. Luis Padrino: Maestro de la Escuela Nueva y fundador de la Educación Rural en Venezuela, 2015, p. 53.

13 Luque, G. Luis Padrino: Fundador de la Educación Rural en Venezuela. Revista de Historia de la Educación. Enero - Diciembre, N 16, 2013, p. 143.

14 El Modelo de la Escuela Nueva llegó a Brasil en la década de 1920, influenciando un importante movimiento social y político en el ámbito de la educación. Han participado en este movimiento intelectuales como Anísio Teixeira, influenciado por las ideas de John Dewey (pragmatista estadounidense), Fernando de Azevedo y Lauro de Oliveira Lima (BRASIL, 2010).

Submetido: 05/05/2018

Aprovado: 05/11/2019

Contato:

Claudio Pinto Nunes

Universidade Estadual do Sudoeste da Bahia (UESB) Programa de Pós-Graduação em Educação (PPGEd)

Estrada do Bem Querer, KM 04

Vitória da Conquista |BA|Brasil

CEP 45.083-900

Fone: (77) 3424-8749

E-mail: ppged@uesb.edu.br 